\title{
Desde dentro y desde fuera: los incas, entre lo emic y lo etic
}

From Within and Without: The Incas, Between Emic and Etic

JAVIER FLORES ESPINOZA

Universidad del Pacifico

flores_jf@up.edu.pe

En 1961 Alfred Métraux publicó Les incas, ${ }^{1}$ un libro de difusión y síntesis de lo que se conocía sobre este pueblo a finales de la década de 1950 . Este pequeño volumen marcó un hito pues fue la primera presentación moderna del mundo incaico hecha para el gran público, y podría además argumentarse que es la mejor presentación de conjunto del incario jamás realizada por un solo investigador (tal vez junto con la de Alan Kolata). ${ }^{2}$ Por ejemplo, su bibliografía, de apenas dos páginas, la mitad de ellas dedicada a fuentes primarias, nos da una idea de cuánto ha cambiado el estado de nuestros conocimientos, ya que hoy en día elaborar algo semejante citando solamente textos de divulgación ocuparía bastante más espacio. Vemos además cuán escasas eran las monografías, pues no había casi nada que citar fuera de los trabajos de John H. Rowe y Sally F. Moore. ${ }^{3}$ Debemos asimismo tener en cuenta que se trata de un libro de divulgación concebido y redactado —espléndidamente, por cierto- antes de la revolución en los estudios incaicos que generaron

1 Métraux 1961, 1969, 1989.

2 Kolata 2013.

3 Moore 1958 y Rowe 1946 (además de Rowe 1944 y 1945, y, sobre los incas coloniales, 1954 y 1957). La evidente omisión bibliográfica es Murra 1956, sin duda porque no había sido publicada.

HISTORIOด XLI.1 (2017): 161-170 / ISSN 0252-8894 
John V. Murra (a quien Métraux agradece aunque no lo cite) y Tom Zuidema, entre otros. ¿¿Pero qué es lo que le da especial categoría a este pequeño volumen? Ante todo que, además de ofrecer una visión global sumamente inteligente del mundo andino a partir de la escasa información en ese momento disponible, Métraux intentó también presentar el conjunto del mundo inca (y el que le antecedió) sin limitarse a retratar el mundo de la nobleza, incluyendo también sendos capítulos en los que se ocupaba del campesinado, la religión y la administración, la imagen de los incas en el Viejo Mundo, ${ }^{4}$ su suerte durante la conquista, su renacimiento y decadencia en la colonia e independencia, y la encrucijada en que se hallaban los quechuas a mediados del siglo XX, signada por su esperanza en el retorno del Inca. Un final sin duda imbuido del espíritu romántico de la época que tan bien plasmó Hergé en Le Temple du Soleil, y que habría de tener gran vigencia en los estudios andinos peruanos.

Mucha agua ha corrido desde que apareciera Les incas y son muchos los investigadores que han presentado su propia visión — de conjunto o monográfica - de este pueblo. ${ }^{5}$ La más reciente y posiblemente más ambiciosa sea The Inka Empire. A Multidisciplinary Approach, una compilación dirigida por Izumi Shimada que consta de 18 textos, además de la introducción del editor. ${ }^{6}$ La primera parte, a cargo de Frank Salomon, Rodolfo Cerrón Palomino, Ken-Ichi Shinoda y Brian Bauer con Douglas K. Smit, se ocupa de las fuentes, la lengua y el origen de los incas, tanto biológico como histórico. En la segunda parte, Alan Covey y Terence D'Altroy se ocupan respectivamente de la administración imperial y del financiamiento del imperio; el tema administrativo, considerado esta vez desde una perspectiva local, reaparece en la cuarta parte, donde Martti Pärssinen, Tamara L. Bray, Inge Schjellerup y Frances M. Hayashida junto con Natalia Guzmán, se ocupan respectivamente del Collasuyu, de la frontera septentrional, de la región de Chachapoyas y de la costa norte. La tercera parte, que se ocupa de «la cultura inca en el centro», examina

4 Hasta ahora no contamos con un estudio para los incas comparable al de Keen 1984.

5 Por ejemplo, Rostworowski 1988, Pease 1998, Pease y otros 2000, D’Altroy 2002 y Kolata 2013, entre otros.

6 Shimada 2015; actualmente se viene preparando una versión ampliada en español. 
el papel de los quipus (Gary Urton), el arte (Thomas B. F. Cummins), la textilería (Elena Phipps) y la arquitectura (Stella Nair y Jean-Pierre Protzen; y Susan A. Niles), así como el culto a los antepasados (Peter Kaulicke) y la cosmología inca, tal como se expresó en Moray (John C. Earls y Gabriela Cervantes). Por último, en la quinta parte, Tetsuya Amino examina la forma en que se fue transformando la concepción y representación de los incas en el virreinato.

Nos encontramos ante una excelente introducción a los estudios del incario, que entreteje la información más reciente con una serie de análisis efectuados desde distintas perspectivas. A semejanza de Métraux, ella no se limita a la época precolombina sino que se adentra en la época virreinal, algo raro en extremo en las visiones panorámicas usuales de los incas, que cuando mucho tocan tímidamente el periodo de la invasión española y a lo más la formación del Estado toledano. ${ }^{7}$ Pero también hay diferencias considerables que se deben no solo al avance de nuestros conocimientos debido al tiempo transcurrido entre ambas publicaciones, sino a que entre ellas media la figura larger than life de Murra. Los investigadores como Métraux y los que le precedieron generalmente combinaron en mayor o menor medida la documentación quinientista con la —aún escasainformación arqueológica y esbozaron imágenes de los incas centradas en el Cuzco. Al preparar su tesis de doctorado, Murra comprendió en cambio que las investigaciones no solo no podían limitarse a una perspectiva cuzcocéntrica, sino que, además, tampoco bastaba con el enfoque arqueológico o con la documentación escrita por sí solos. Sostuvo, por ello, que «la comprensión plena del Estado inka» requería lo que llamó «un enfoque interdisciplinario que incorporase la etnohistoria, la etnología, la etnobotánica y la arqueología, pero no otras ciencias naturales o sociales». ${ }^{8}$ Es este plan implícito, devenido en programa, el que ha guiado los estudios andinos durante el último medio siglo.

7 Véase, por ejemplo, D’Altroy 2002, Kolata 2013, Patterson 1991, Pease 1998 y Rostworowski 1988.

8 Barnes 2010. Todas las traducciones son mías. Barnes limita su examen a la influencia del plan de Murra en Craig Morris y John Hyslop. Me parece que la influencia de dicho plan puede ser extendida a la mayoría de los investigadores del incario. 
La compilación que ahora comentamos representa en cierto sentido la culminación del mismo, ya que encontramos en ella esa combinación de diversas perspectivas con un enfoque que examina tanto al Cuzco como a las provincias.

Infortunadamente no tengo espacio para resumir The Inka Empire o comentar todos sus capítulos. Me interesa más bien apuntar a un problema - no un defecto- de su concepción. En la introducción, Shimada señala que el origen de esta compilación se remonta a finales de la década de 1970, cuando quedó convencido de que la «comprensión holista de sistemas complejos como el Imperio inka requiere de un enfoque multidisciplinario que brinde percepciones y conocimientos sinérgicos, así como la capacidad de verificar y refinar diversas líneas de prueba». ${ }^{9}$ Este volumen busca por ello demostrar cuán importante es la colaboración entre distintas disciplinas, algo en lo que sin duda ha tenido éxito. Resulta asimismo claro que no existe «un enfoque de los estudios incaicos, o uso de las fuentes textuales, que sea superior», razón por la cual se debe aplicar, una vez más, un «enfoque multidisciplinario amplio [...] en el cual cada línea de evidencia, la etnohistórica inclusive, se examine y contraste independientemente con otras lineas de evidencia», ${ }^{10}$ objetivo también alcanzado aquí al reunir textos en permanente diálogo y contraste. Además Shimada y Cerrón Palomino sugieren, a partir del trabajo de este último, que es hora de reevaluar «el enfoque dual (arqueología/etnohistoria) profundamente arraigado de los estudios del pasado andino» ${ }^{11}$ y añadir a la lingüística como tercer eje, como Murra sugiriera ya en su necrología de John Hyslop. ${ }^{12}$ En efecto, en su búsqueda de cuál fue la llamada «lengua secreta de los Incas», Cerrón halló una estratificación lexical a partir de la cual vio que el puquina habría sido la lengua original de los antepasados de los incas, quienes habrían adoptado luego el aimara al emigrar al Cuzco y solamente asumieron el quechua como lengua administrativa durante el reinado de Túpac Inca Yupanqui.

9 Shimada 2015: 2.

${ }^{10}$ Ib.: 7; subrayado en el original.

${ }^{11}$ Ib.: 7 .

${ }^{12}$ Murra 1994: 2; y Barnes 2010. 
Este breve resumen no hace justicia a la riqueza del estudio de Cerrón pero sí deja claro que tiene razón cuando afirma que debemos prestar mucha más atención tanto a la lingüística como a la filología, que hasta ahora en general son tratadas como "ciencias auxiliares» y no como disciplinas que por derecho propio pueden efectuar una contribución decisiva al conocimiento del mundo andino. Esto no significa desmerecer las contribuciones efectuadas por muchos lingüistas como Alfredo Torero, Gerald Taylor o César Itier, ${ }^{13}$ entre otros; quiere decir más bien que en los estudios andinos, como regla general hasta hoy, el quechua y las demás lenguas andinas solamente aparecen como fuentes de datos discretos recogidos en los diccionarios coloniales porque la mayoría de los investigadores — me incluyo — no podemos hablar ninguna de ellas. ${ }^{14}$

El desconocimiento de las lenguas andinas acentúa la distancia que nos separa de los incas y las culturas antiguas del Perú. Pero también tiende a profundizar la escisión de los estudios del Ande que se remonta al plan maestro de investigación de Murra. Aunque dicho plan, tal como fue diseńado, era lo suficientemente flexible como para que cobijara distintas propuestas, el zeitgeist de la época tendía a privilegiar el estudio de la materialidad y de lo objetivo. De este modo, fue construyéndose una imagen del mundo andino elaborada desde fuera, que se contraponía con la imagen desde dentro que Zuidema y sus alumnos intentaban construir. Esto nos lleva al viejo dilema de lo etic contrapuesto a lo emic. Curiosamente, en los Andes estas dos perspectivas tendieron a combinarse; tuvimos así una aproximación etic —objetiva y de fuera - del estudio de la cultura y la historia, que coexistía lado a lado con un enfoque emic de la civilización andina en la longue durée - lo «andino»— que usualmente, mas no siempre, terminaba elaborando un constructo ahistórico y atemporal. Sin embargo, gradualmente el enfoque etic fue ganando preeminencia, incluso en aquellos trabajos que buscaban entender las concepciones andinas, de modo tal que el análisis se hacía guiado por categorías occidentales (religión, arte, política).

13 Torero 1974, 2002; Taylor 2000; e Itier 2011 y 2013.

${ }^{14}$ El mismo Murra no llegó a aprender el quechua (Barnes 2010). 
Eso permitía que, por ejemplo, se estudiaran las «bases cosmológicas de la autoridad y la identidad en los Andes» sin tener en cuenta al parentesco, aun sabiendo que el conjunto de la cultura del mundo precolombino se expresaba fundamentalmente a través del lenguaje del parentesco. ${ }^{15}$ Lo mismo sucede en The Inka Empire, donde no encontramos un estudio de esta temática, omisión que resulta tanto más grave cuanto que Itier ha mostrado que las panacas "no existieron», ${ }^{16}$ lo que obliga a realizar un reexamen de todo este tema. De otro lado, las categorías con las que esta compilación fue armada provienen en última instancia de una visión etic en constante tensión con lo que los distintos autores van señalando. Esto es particularmente notorio en los capítulos de la tercera parte (para mí, una de las más interesantes), donde la exposición constantemente desborda el marco analítico occidental. ${ }^{17}$ Cabría preguntarnos por ello si un inca se reconocería a sí mismo y a su cultura en la abundante bibliografía actualmente existente (mi respuesta es que sí, aunque con bastante dificultad).

Se entiende entonces por qué resulta tan interesante la aparición del libro de Isabel Yaya, The Two Faces of Inca History: Dualism in the Narratives and Cosmology of Ancient Cuzco. ${ }^{18}$ La autora busca comprender cómo era que en el Tahuantinsuyo se construía la identidad de su élite "a través de medios narrativos, rituales y cosmológicos» ${ }^{19}$ y se concentra por ello en la narrativa que los incas tuvieron de su pasado. Pero ella no está a la caza de la historia de los incas (en sentido occidental); lo que le interesa más bien es «desembrollar cómo era que [estos] se relacionaban con su pasado, así como esbozar los contornos de formas alternativas de representación histórica» a través del «estudio del parentesco incaico, en particular el examen de las normas de descendencia regias, la transmisión de

${ }^{15}$ Ramírez 2005. En respuesta a esta crítica, Ramírez me dijo que hoy (2015) escribiría el libro de modo del todo distinto.

${ }^{16}$ Itier 2011; Hernández 2012 también ha examinado este problema.

17 Véase, por ejemplo, el capítulo de Cummins dedicado al arte (Shimada 2015: 165-196).

${ }^{18}$ Yaya 2012.

${ }^{19}$ Ib.: 22. Dejo íntegramente de lado sus objetivos referidos a la teoría antropológica. 
nombres y las preferencias matrimoniales», ${ }^{20}$ empleando la «organización dual» y la «lente de las oposiciones duales» como marco conceptual. ${ }^{21}$ El resultado es un libro bastante denso y complejo, imposible de resumir aquí, que será más accesible para los antropólogos que los historiadores. Me interesa, sí, resaltar un solo aspecto. Yaya parte del supuesto de que había una forma de conciencia histórica inca que podemos recuperar "por mucho que haya sido forzada [dentro de] categorías ajenas». ${ }^{22}$ Esta conciencia histórica se expresaba en cantos que guardaban la memoria de, y honraban a, jefes locales dignos de ser recordados por haber servido bien a su comunidad, pero sin jamás llegar a ser «un registro exhaustivo de la historia incaica [...] sino una evaluación selectiva de los logros alcanzados por una figura ancestral». Y dado que estos registros eran guardados por las panacas en "esta sociedad altamente estratificada en donde los lazos de parentesco y el mérito excepcional definían el acceso a la autoridad», dichas narrativas buscaban «adular a los miembros de familias [households] regias específicas». ${ }^{23}$ Esto explica las constantes contradicciones con que nos topamos en las crónicas, debidas a que los incas no buscaban preservar toda la historia, sino solo las historias que le interesaban a un grupo específico. Y explica también que los acontecimientos que ellas registraban no necesariamente eran obra de una sola persona, sino de varias generaciones. ${ }^{24}$

No tenemos espacio para examinar la relación que Yaya establece entre la historia incaica y el clan cónico, ${ }^{25} \mathrm{ni}$ tampoco la pertinencia del uso del término "historia» para denominar las narrativas incas en lugar de «mitohistoria», pero sí para resaltar que, independientemente de las críticas que se le puedan hacer, es un valioso intento de ver su objeto de estudio desde adentro. Nos falta un estudio de síntesis de este tipo,

${ }^{20}$ Ib.: 259.

${ }^{21}$ Ib.: 6 y 18 , respectivamente.

${ }^{22}$ Ib.: 17.

${ }^{23}$ Ib.: 45-46.

${ }^{24}$ Ib.: 261.

${ }^{25}$ Queda por resolver en qué medida sobrevive la tesis de Yaya ahora que Itier (2011) ha demostrado que las panacas no existieron como grupos de linajes o de parientes. 
que nos muestre la sociedad y la cultura incaicas desde una perspectiva emic; los dos volúmenes que hemos comentado constituyen un paso importante en dicha dirección.

Quiero mencionar, para terminar, que Luis Guillermo Lumbreras alguna vez sostuvo que era hora de escribir un «Indian's handbook of South America». ${ }^{26}$ En ese entonces no le di la debida importancia. Pero llama la atención que los libros publicados en el extranjero sobre el Perú antiguo cada vez marginen más a los autores peruanos. En el caso de The Inka Empire, dos de los autores peruanos (apenas tres) aparecen como segundo autor. Cierto es que el compilador tiene el derecho de invitar a colaborar a quien a él o ella le parezca. Pero me cuesta creer que no haya ningún otro investigador peruano que mereciera ser incluido (me viene inmediatamente a la cabeza el nombre de Julián Santillana). Y me llama aún más la atención que, en un trabajo que anuncia como objetivo «familiarizar a los lectores con importantes avances [scholarship] en los estudios inkas efectuados por estudiosos en diversas partes del mundo cuyas publicaciones a menudo no aparecen en inglés, y/o no tienen una amplia distribución fuera de su país», ${ }^{27}$ se ignore - en el caso del estudio de los incas en la colonia- el trabajo de autores como Gabriela Ramos ${ }^{28}$ y Juan Carlos Estenssoro. ${ }^{29}$ Cuesta no ver en esto una forma de colonialismo.

\section{BIBLIOGRAFÍA}

Barnes, Mónica. 2010. «John Victor Murra’s Master Research Plan and the Work of Craig Morris and John Hyslop» [Manuscrito].

D'Altroy, Terence N. 2002. The Incas. Malden: Blackwell.

Estenssoro Fuchs, Juan Carlos. 2003. Del paganismo a la santidad. La incorporación de los indios del Perú al catolicismo, 1532-1750. Lima: Instituto Francés de Estudios Andinos, Instituto Riva-Agüero y Pontificia Universidad Católica del Perú. https:// doi.org/10.4000/books.ifea.4412

\footnotetext{
${ }^{26}$ Lumbreras 1981.

27 Shimada 2015: 4.

${ }^{28}$ Ramos 2005.

${ }^{29}$ Estenssoro 2003 y 2005.
} 
. 2005. «Construyendo la memoria: la figura del Inca y el reino del Perú, de la conquista a Túpac Amaru II». En Majluf, Natalia y otros. Los Incas, reyes del Perú. Lima: Banco de Crédito del Perú, 94-173.

Hernández, Francisco. 2012. Los incas y el poder de sus ancestros. Lima: Pontificia Universidad Católica del Perú.

Itier, César. 2011. «Las panacas no existieron». En Adelaar, Willem; Valenzuela, Pilar y Roberto Zariquiey (eds.). Estudios sobre lenguas andinas y amazónicas. Homenaje a Rodolfo Cerrón-Palomino. Lima: Pontificia Universidad Católica del Perú, 181-193.

2013. Viracocha o el océano: naturaleza y funciones de una divinidad inca.

Lima: Instituto Francés de Estudios Andinos e Instituto de Estudios Peruanos.

Keen, Benjamin. 1984. La imagen azteca en el pensamiento occidental. México, D. F.: Fondo de Cultura Económica.

Kolata, Alan L. 2013. Ancient Inca. Nueva York: Cambridge University Press.

Lumbreras, Luis Guillermo. 1981. Arqueología de la América andina. Lima: Editorial Milla Batres.

Métraux, Alfred. 1961. Les incas. París: Editions Le Seuil. . 1969. The History of the Incas. Traducido del francés por George Ordish. Nueva York: Schocken Books.

. 1989. Los incas. Epílogo de Abdón Yaranga Valderrama. México, D. F.: Fondo de Cultura Económica.

Moore, Sally Falk. 1958. Power and Property in Inka Peru. Nueva York: Columbia University Press.

Murra, John V. 1956. The Economic Organization of the Inca State. Tesis de Ph.D. Chicago: Universidad de Chicago. . 1994. «John Hyslop 1945-1993». Andean Past. Vol. 4: 1-7.

Patterson, Thomas C. 1991. The Inca Empire. The Formation and Disintegration of a Pre-Capitalist State. Nueva York y Oxford: Berg.

Pease, Franklin. 1998. Los incas: una introducción. Lima: Fondo Editorial de la Pontificia Universidad Católica del Perú.

Pease, Franklin y otros. 2000. Los incas: arte y símbolos. Lima: Banco de Crédito del Perú.

Ramírez, Susan. 2005. To Feed and be Fed. The Cosmological Bases of Authority and Identity in the Andes. Stanford: Stanford University Press.

Ramos, Gabriela. 2005. "Los símbolos de poder inca durante el virreinato». En Majluf, Natalia y otros. Los Incas, reyes del Perú. Lima: Banco de Crédito del Perú, 43-65.

Rostworowski, María. 1988. Historia del Tahuantinsuyu. Lima: Instituto de Estudios Peruanos. 
Rowe, John Howland. 1944. "An Introduction to the Archaeology of Cuzco». Papers of the Peabody Museum of American Archaeology and Ethnology. Vol. XXVII, núm. 2.

1945. "Absolute chronology in the Andean area». American Antiquity. Vol. X, no. 3: 265-84. https://doi.org/10.2307/275130

. 1946. «Inca Culture at Time of the Spanish Conquest». En Steward, Julian H. (ed.). Handbook of South American Indians. Washington, D. C.: Bureau of American Ethnology, vol. 2, 183-331.

. 1954. «El movimiento nacional inca del siglo XVIII». Revista Universitaria. Año XLIII, núm. 107: 17-47.

. 1957. «The Incas Under Spanish Colonial Institutions». The Hispanic American Historical Review. Vol. 37, núm. 2: 155-199. https://doi. org/10.2307/2510330

Shimada, Izumi (ed). 2015. The Inka Empire. A Multidisciplinary Approach. Austin: University of Texas Press.

Taylor, Gerald. 2000. Camac, camay y camasca y otros ensayos sobre Huarochirí y Yauyos. Cuzco: Instituto Francés de Estudios Andinos y Centro de Estudios Regionales Andinos Bartolomé de Las Casas.

Torero, Alfredo. 1974. El quechua y la historia social andina. Lima: Universidad Ricardo Palma.

. 2002. Idiomas de los Andes: lingüistica e historia. Lima: Instituto Francés de Estudios Andinos y Editorial Horizonte.

Yaya, Isabel. 2012. The Two Faces of Inca History: Dualism in the Narratives and Cosmology of Ancient Cuzco. Leiden y Boston: Brill. https://doi. org/10.1163/9789004233874 